\title{
Heparin-binding Ligands Mediate Autocrine Epidermal Growth Factor Receptor Activation In Skin Organ Culture
}

\author{
Stefan Stoll, ${ }^{\star}$ Warren Garner, ${ }^{\ddagger}$ and James Elder ${ }^{\star \S}$ \\ $*$ Department of Dermatology, ${ }^{\ddagger}$ Department of Surgery, and ${ }^{\S}$ Department of Radiation Oncology (Cancer Biology), University of \\ Michigan, Ann Arbor, Michigan 48109
}

\begin{abstract}
Exogenous EGF and TGF- $\alpha$ accelerate wound healing, but treatment effects are often modest. Using short-term human skin organ culture, we found that autocrine EGF receptor activation could account for this observation. Amphiregulin and heparin-binding EGF-like growth factor (HB-EGF) transcripts were rapidly and markedly induced, whereas EGF and TGF- $\alpha$ mRNAs were undetectable or only slightly increased. Vascular permeability factor and keratin 6 transcripts were also strongly induced, albeit with $\mathrm{a} \geq 3 \mathrm{~h}$ delay relative to HB-EGF and amphiregulin. All four transcripts were upregulated in actual healing skin wounds, HB-EGF and keratin 6 being the most prominent. The highly EGF receptor-specific tyrosine kinase inhibitor PD153035 strongly inhibited induction of all four transcripts in organ culture, as well as release of immunoreactive HB-EGF into the medium. These effects were confirmed using the anti-EGF receptor mAb 225 IgG. Neither PD153035 nor 225 IgG was toxic to keratinocytes, as judged by calcein-AM uptake. PD153035 completely abrogated the proliferative phase of keratinocyte outgrowth in skin explant cultures, whereas it had no effect on the antecedent migratory phase. Based on these results, we conclude that EGF receptor activation by highly inducible, keratinocyte-derived heparin-binding ligands is an important mechanism for amplification and transmission of the cutaneous wound healing signal. (J. Clin. Invest. 1997. 100:1271-1281.) Key words: wound healing • skin • receptor protein tyrosine kinase $\cdot$ epidermal growth factor urogastrone receptor $\bullet$ transforming growth factor alpha
\end{abstract}

\section{Introduction}

Cutaneous wound healing requires precise coordination of keratinocyte migration and proliferation, vascular permeability

Some of this material has been presented in abstract form: see $J$. Investig. Dermatol. 104:678A, 1995; and J. Investig. Dermatol. 106:820, 1996.

Address correspondence to Dr. James T. Elder, 3312 CCGC, Box 0932, University of Michigan, Ann Arbor, MI 48109-0932. Phone: 313-763-0355; FAX: 313-763-4575; E-mail: jelder@umich.edu

Received for publication 14 January 1997 and accepted in revised form 23 June 1997.

J. Clin. Invest.

(C) The American Society for Clinical Investigation, Inc. 0021-9738/97/09/1271/11 \$2.00

Volume 100, Number 5, September 1997, 1271-1281

http://www.jci.org and angiogenesis, inflammatory and immune responses, and connective tissue remodeling (1). Each of these events is carried out by cells expressing distinctive patterns of motility, biosynthesis, and proteolytic activity, which can be thought of as lineage-specific pathways of terminal differentiation (2). Several lines of evidence suggest that growth factors might play an important role in coordinating these events. Numerous growth factors and/or their receptors are upregulated in the wound environment, and exogenous growth factors significantly accelerate the healing of cutaneous wounds (1). Conversely, targeted expression of dominant-negative growth factor receptor mutants in transgenic mice substantially delays wound reepithelialization (3).

Keratinocytes produce a number of growth factors, among which members of the EGF family are prominent: TGF- $\alpha$, amphiregulin (AR), ${ }^{1}$ and heparin-binding EGF-like growth factor (HB-EGF) $(4,5)$. Epidermal growth factor receptor (EGFR) activation causes autoinduction of multiple EGF family members in keratinocytes (6-9) via a mechanism primarily involving mRNA stabilization $(10,11)$. Indicative of relevance to the in vivo situation, one or more of these ligands are overexpressed in a number of dermatoses characterized by epidermal hyperproliferation (4). In addition to these EGF-like factors, a more distantly related family of EGF-like growth factors (neu differentiation factors (NDFs)/heregulins) can interact in a complex fashion with additional members of the EGFR family (HER2, 3, and 4). These receptors may be present as homodimers or heterodimers, depending on cell type (12). HER2 and HER3 are expressed in skin (13), and HER3 is upregulated in the neoepidermis of healing wounds (14). NDF- $\alpha_{2}$ appears to be an important paracrine mediator of wound healing (14). Three lines of evidence, however, argue that among the four HERs, only the prototypical EGFR (c-erbB1/HER1) is subject to autocrine activation in keratinocytes. First, highly specific anti-EGFR mAbs abrogate clonal keratinocyte proliferation in the absence of fibroblast feeder layers $(15,16)$. Second, keratinocyte proliferation was not significantly increased in NDF- $\alpha_{2}$-treated wounds, whereas increased expression of the keratinocyte differentiation markers K10 and filaggrin was observed in seven of eight wounds (14). Third, ligand activation of HER2/HER3 is not mitogenic for keratinocytes cultured in serum-free medium (13).

Beginning with the classical studies of Cohen and colleagues, it has been evident that exogenous EGF exerts profound effects on tissue remodeling during development (17). More recently, several lines of molecular evidence identify

1. Abbreviations used in this paper: AR, amphiregulin; EGFR, EGF receptor, HB-EGF, heparin-binding EGF-like growth factor; K6, keratin 6; NDF, neu differentiation factor; RT-PCR, reverse transcription PCR; VPF, vascular permeability factor. 
EGFR activation as central to the early stages of wound healing: (a) EGFR expression is upregulated early in wound healing, and precedes the hypertrophic response (18); (b) vascular permeability factor (VPF), a direct mediator of permeability and angiogenesis in microvascular endothelial cells, is induced by EGF or TGF- $\alpha$ treatment of cultured keratinocytes (19); (c) the keratin 6 (K6) and K16 genes, which are markedly upregulated in the differentiating keratinocytes of healing wounds $(2,20)$, contain upstream regulatory elements responsive to EGFR activation (21); and (d) urokinase plasminogen activator, which is responsible for localized activation of type IV collagenase, diverse metalloproteinases, and TGF- $\beta$ (22, 23 ), in addition to its role in fibrinolysis (24), is strongly upregulated in EGF-treated keratinocytes and in healing wounds (25). More directly, EGF and TGF- $\alpha$ have both been shown to accelerate significantly the healing of cutaneous wounds in several species, including humans (26). Even after exposing wounds to large quantities of EGF and $\mathrm{TGF}-\alpha$ via recombinant technology however, clinically relevant increases in epidermal wound healing rates have been difficult to document, despite careful studies (27).

Given the clear evidence for marked responsiveness of cultured keratinocytes to EGF and TGF- $\alpha(7,28)$, the modest enhancement of epidermal wound healing in response to these ligands seemed paradoxical. Recalling the evidence for autoinduction of EGFR ligands in keratinocytes cited above, we hypothesized that enhanced expression of one or more EGFR ligands might occur during wound healing, thus obscuring the effects of exogenous ligands. To test this hypothesis in human skin, we have used three complementary experimental systems: $(a)$ a short-term skin organ culture model previously developed in our laboratory (29); (b) an epidermal outgrowth model originally developed for porcine skin (30); and (c) direct analysis of previously wounded human skin (31). By applying highly specific inhibitors of EGFR signal transduction to the first two of these systems, here we provide evidence that autocrine EGFR activation is critical for both amplification and transmission of the wound-healing signal.

\section{Methods}

Materials. The specific EGFR tyrosine kinase inhibitor PD153035 (32) and its biologically inactive congener PD153240 were the generous gifts of Drs. D. Fry and W.R. Leopold (Parke-Davis, Warner Lambert Co., Ann Arbor, MI). The anti-EGFR mAb 225 IgG (33) was kindly provided by Dr. John Mendelsohn (Memorial Sloan-Kettering Cancer Center, New York). EGF, TGF- $\alpha$, TGF- $\beta 1$, heparinbinding EGF (HB-EGF), and a polyclonal antibody directed against HB-EGF were purchased from R\&D Systems (Minneapolis, MN). MOPC21 and horseradish peroxidase-conjugated rabbit anti-goat antibodies were from Cappel-Organon Teknika (Durham, NC). Restriction and modifying enzymes were obtained from Gibco BRL (Gaithersburg, MD) or Boehringer Mannheim Biochemicals (Indianapolis, IN). Radiochemicals were purchased from Amersham Corp. (Arlington Heights, IL). All other biochemicals were reagent grade.

Skin biopsies and grafts. After obtaining informed consent, normal skin tissue was harvested from the buttocks of healthy volunteers by keratome biopsy at a depth of $0.2-0.4 \mathrm{~mm}$ as previously described (34). Actively reepithelializing split thickness skin graft donor sites were harvested by keratome $6 \mathrm{~d}$ after removal of the original graft for surgical reconstruction of burn wounds, as previously described (31). All biopsy protocols were approved by the Institutional Review Board of the University of Michigan.
Cell culture. Suspensions of normal adult human keratinocytes were prepared from keratome biopsies by overnight trypsin flotation (35). Suspensions were then either cultured directly in low-calcium, serum-free MCDB 153 medium supplemented essentially as described (36) (KGM ${ }^{\mathrm{TM}}$; Clonetics, San Diego, CA) (MCDB keratinocytes [MCDB-KC]), or cocultured with irradiated 3 T3 fibroblast feeder layers in 3:1 DMEM:F12 medium supplemented with 5\% FBS, insulin $(5 \mu \mathrm{g} / \mathrm{ml})$, EGF $(10 \mathrm{ng} / \mathrm{ml})$, hydrocortisone $(0.4 \mu \mathrm{g} / \mathrm{ml})$, adenine $(0.18 \mathrm{mM})$, cholera toxin $(0.1 \mathrm{nM})$, and antibiotics as described (28) (Rheinwald-Green keratinocytes [RWG-KC]). Second to fourth passage subcultures of MCDB-KC were rendered quiescent by deprivation of growth factors for $48 \mathrm{~h}$, then treated with EGF or TGF- $\alpha$ as described (15). RWG-KC were studied $10 \mathrm{~d}$ after confluence, without growth factor deprivation. $30 \mathrm{~min}$ before growth factor treatment (MCDB-KC) or at various times before harvest (RWG-KC), cultures were pretreated with $5 \mu \mathrm{g} / \mathrm{ml}$ of the anti-EGFR mAb $225 \mathrm{IgG}$ or MOPC21 isotype control, with various concentrations (1-1000 nM) of the tyrosine kinase inhibitor PD153035 (32), or 1,000 nM of the inactive congener PD153240.

Organ culture. Keratome strips were either frozen immediately in liquid nitrogen or transported to the laboratory in modified basal MCDB153 medium (KBM ${ }^{\mathrm{TM}}$; Clonetics, or Medium 154; Cascade Biologics, Portland, OR) within $15 \mathrm{~min}$ at room temperature. Upon arrival in the laboratory, tissue samples were trimmed to the appropriate size $\left(1-2 \mathrm{~cm}^{2}\right)$ for RNA isolation, or left as $7.5-\mathrm{cm}^{2}$ strips for HB-EGF protein assay. Tissue fragments were floated, stratum corneum side up, in 35-mm dishes containing $\mathrm{KBM}$ and the indicated additives in a $5 \% \mathrm{CO}_{2}$ incubator at $37^{\circ} \mathrm{C}$. Samples were treated with $225 \mathrm{IgG}$ or MOPC21 isotype control $(80 \mu \mathrm{g} / \mathrm{ml})$, or with various concentrations of PD153035 (10-10,000 nM). After various times, the tissue samples were snap-frozen in liquid nitrogen and processed for RNA isolation or immunoreactive HB-EGF as described below. Cell viability in keratome biopsy fragments was tested using the LIVE/DEAD cytotoxicity kit (Molecular Probes, Inc., Eugene, OR), according to the manufacturer's instructions.

Epidermal outgrowth assay. Keratome biopsies $(0.2-0.4 \mathrm{~mm}$ thickness, $0.5 \mathrm{~cm}^{2}$ ) were gently smeared onto acid-washed, autoclaved glass microscope slides, air-dried for $10 \mathrm{~min}$, then placed in 100-mm tissue culture dishes and gently overlaid with RPMI 1640 medium (Gibco BRL) containing 1\% FBS, TGF- $\beta 1$ ( $2 \mathrm{ng} / \mathrm{ml})$, EGF $(5 \mathrm{ng} / \mathrm{ml})$, penicillin $(200 \mathrm{U} / \mathrm{ml})$, streptomycin $(200 \mu \mathrm{g} / \mathrm{ml})$, and amphoterecin B (500 ng/ml) as previously described (30), except that human rather than porcine skin was used. Explants were incubated at $37^{\circ} \mathrm{C}, 5 \%$ $\mathrm{CO}_{2}$ for $0-8 \mathrm{~d}$, in the presence of $300 \mathrm{nM}$ PD153035 or DMSO vehicle, with change of medium every other day. As preliminary studies indicated that PD153035 tended to lose biological activity with time (see Results), the medium was replenished with $300 \mathrm{nM}$ fresh drug or DMSO vehicle daily. Representative outgrowths were photographed, and the maximum width and height of contiguous keratinocyte sheets were measured after projection at a fixed distance. Outgrowth area was approximated as the product of the width and height measurements. Individual cells and cells attached only by extended processes were excluded from the area measurements, however, their inclusion had no effect on the outcome of significance tests, as judged by the time points yielding $P<0.05$. Two to six separate outgrowths arising from a single keratome fragment were measured, and their areas were averaged. The effects of PD153035 on average outgrowth area as a function of time was assessed using a paired $t$ test.

Plasmids and hybridization probes. The cDNA plasmids phEGF116, pSP65TGF- $\alpha$, and p36B4 were the generous gifts of Drs. Graeme Bell (Howard Hughes Medical Institute, University of Chicago, IL), Rik Derynk (University of California, San Francisco, CA), and Sam Lee (Harvard Medical School, Boston, MA), respectively, and their use has been previously described $(37,38)$. The 1.9-kb HB-EGF and 0.9-kb AR cDNAs were isolated from a $\lambda \mathrm{gt} 11$ human keratinocyte cDNA library (Clontech, Palo Alto, CA) by screening with ${ }^{32} \mathrm{P}$ labeled oligonucleotides end-labeled using T4 polynucleotide kinase and $\gamma\left[{ }^{32} \mathrm{P}\right] \mathrm{ATP}$, or reverse transcriptase (RT)-PCR products uni- 
formly labeled prepared by random priming using $\alpha\left[{ }^{32} \mathrm{P}\right] \mathrm{dCTP}$. The 299-bp VPF and 234-bp K6 PCR probes were prepared by direct amplification of the same human keratinocyte cDNA library. Bacteriophage inserts and PCR products were subcloned into pUC19 (Boehringer Mannheim Biochemicals) or pCR $^{\mathrm{TM}}$ II (Invitrogen Corp., San Francisco, CA), and their identities were confirmed by DNA sequencing (data not shown). Oligonucleotide primers were derived from residues 329-350 (forward) and 720-699 (reverse) of the AR cDNA sequence (39), from position 489-509 (forward) and 1755-1735 (reverse) of the HB-EGF cDNA sequence (Genbank accession number M60278) and from position 177-197 (forward) and 476-456 (reverse) of the VPF sequence (40). Oligonucleotide primers specific for K6a were derived from residues 1307-1326 (forward) and 1521-1540 (reverse) in the $3^{\prime}$ noncoding region (Genbank accession number V01516). cDNA inserts were prepared by restriction endonuclease digestion, gel-purified using Geneclean ${ }^{\mathrm{TM}}$ (Bio101, La Jolla, $\mathrm{CA})$ and ${ }^{32} \mathrm{P}$-labeled to a specific activity of $5-7 \times 10^{9} \mathrm{cpm} / \mu \mathrm{g}$ by random priming. All molecular biological manipulations used standard protocols (41).

RNA isolation and northern blotting. Total RNA was prepared from snap-frozen tissue by the guanidinium isothiocyanate-cesium chloride technique as described (29), except that cesium trifluoroacetate (Pharmacia LKB Biotechnology, Inc., Piscataway, NJ) was used in place of cesium chloride. RNA was isolated from keratinocytes using RNAzol (Tel-Test, Friendswood, TX) according to the manufacturer's instructions. 30-40 $\mu \mathrm{g}$ of total RNA (determined by $\mathrm{OD}_{260}$ ) was electrophoretically separated on $1 \%$ formaldehyde-agarose gels, transferred to derivitized nylon membranes (Zeta-Probe; Bio-Rad Laboratories, Richmond, CA), prehybridized, hybridized, autoradiographed, and stripped for rehybridization exactly as previously described (29). Hybridization signals were visualized by autoradiography and/or quantified by phosphorimager (Molecular Dynamics, Inc., Sunnyvale, CA). Quantitated hybridization signals were normalized to the control gene 36B4, and expressed relative to the values obtained for non-organ-cultured skin from the same individual. Alterations in gene expression due to the $225 \mathrm{IgG}$ and PD153035 treatment were expressed as a percentage of the -fold induction value obtained for untreated controls. Statistical analysis was by ANOVA.

$H B-E G F$ immunoassay. $15 \mathrm{~cm}^{2}$ of keratome organ culture (two keratome strips) were floated on $10 \mathrm{ml}$ of basal modified MCDB 153 medium. After $3 \mathrm{~d}$ of incubation at $37^{\circ} \mathrm{C}, 5 \% \mathrm{CO}_{2}$, the dishes were removed from the incubator, and $5 \mathrm{ml}$ of $4 \mathrm{M} \mathrm{NaCl}$ was added to each dish with gentle agitation for $5 \mathrm{~min}$ at room temperature. The liquid was then decanted, centrifuged for $15 \mathrm{~min}$ at $3000 \mathrm{~g}$, filtered using 0.2 $\mu \mathrm{m}$ filters (Acrodisc; Gelman Sciences, Inc., Ann Arbor, MI), concentrated using Centriplus concentrators (Amicon, Beverly, MA) and rotated at $4^{\circ} \mathrm{C}$ overnight with $200 \mu l$ heparin-sepharose suspension (Pharmacia LKB Biotechnology) according to the manufacturer's instructions. After washing once for $10 \mathrm{~min}$ in $10 \mathrm{ml}$ of 100 $\mathrm{mM} \mathrm{NaCl}, 10 \mathrm{mM} \mathrm{NaPO}$, $\mathrm{pH} 7.3$ at room temperature, heparinbinding proteins were directly eluted into Laemmli sample buffer (42) by boiling for $10 \mathrm{~min}$, subjected to SDS-PAGE using precast 14\% Tris-glycine gels (Novex, San Diego, CA) and transferred to PVDF membranes using a semi-dry blotting apparatus (Bio-Rad Laboratories). Filters were blocked for $1 \mathrm{~h}$ in Dulbecco's PBS without calcium and magnesium, with $0.1 \%$ Tween-20 (PBST) and $10 \%$ nonfat dry milk, then decorated overnight at $4^{\circ} \mathrm{C}$ with $1.5 \mu \mathrm{g} / \mathrm{ml}$ goat anti-HB-EGF polyclonal antibody (R\&D Systems, Minneapolis, $\mathrm{MN}$ ) in PBST with $1 \%$ nonfat dry milk. After two 15 -min washes in PBST with $5 \%$ nonfat dry milk, membranes were incubated with 1 $\mu \mathrm{g} / \mathrm{ml}$ horseradish peroxidase-conjugated rabbit anti-goat IgG (Cappel-Organon Teknika) in PBST-5 for $1 \mathrm{~h}$ at room temperature and washed twice in PBST-5 as described above. Detection was performed using the ECL system (Amersham Corp.), according to manufacturer's instructions. Immunoreactive HB-EGF was quantitated by densitometer (Molecular Dynamics) by comparison to known amounts of recombinant human HB-EGF standard. Densitometric signals for the standards displayed a linear response over the range of

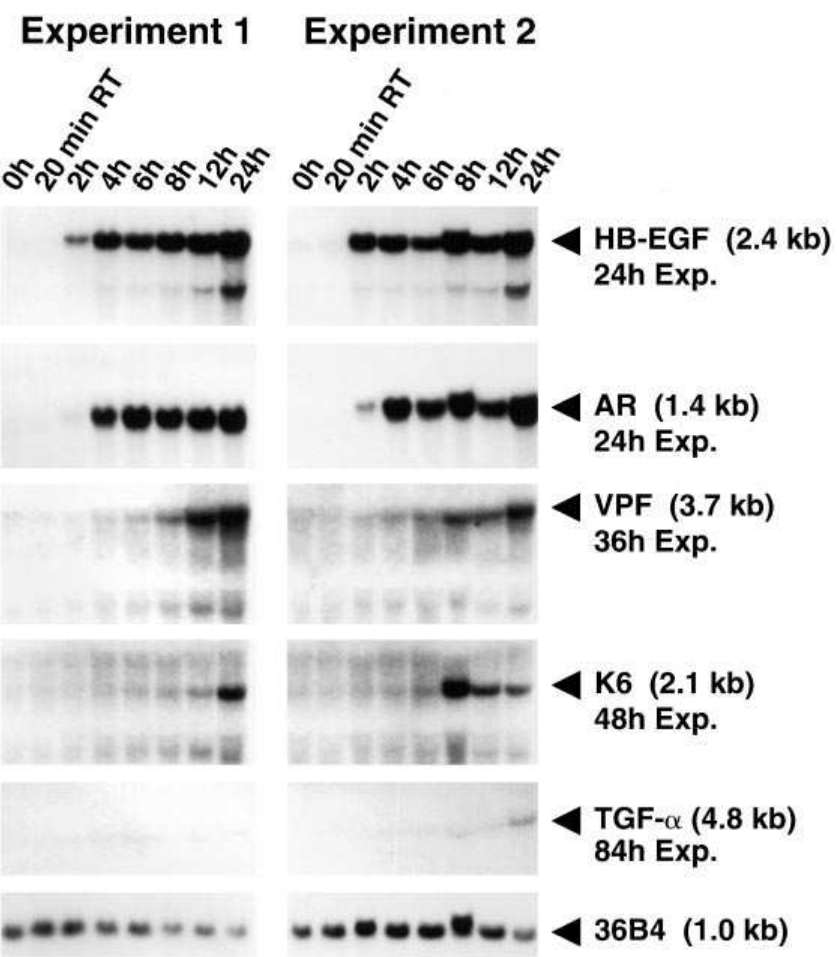

Figure 1. HB-EGF, AR, VPF, and K6 expression in organ cultures of human skin. After incubating biopsies at $37^{\circ} \mathrm{C}$ in $\mathrm{KBM}$ for the times indicated at the top of the figure, total RNA was extracted and analyzed by Northern blotting. Sequential rehybridizations of the same blot are shown. Experiment 1 and Experiment 2 depict results derived from two different individuals. Hybridization probes, transcript size, and exposure times are indicated on the right. Results shown are representative of four experiments, in all of which induction of HBEGF and AR preceded comparable inductions of VPF and K6 by at least $3 \mathrm{~h}$.

0-500 pg (data not shown). Statistical analysis was by paired Student's $t$ test.

\section{Results}

Expression of EGF-like growth factors, VPF, and K6 in human skin organ culture. HB-EGF, AR, TGF- $\alpha$, VPF, and K6 mRNA levels were minimal to undetectable in keratomes snap-frozen at the time of biopsy, or after maintenance at room temperature for up to $2 \mathrm{~h}$ (Figs. 1 and $2 A$ ). Increased amounts of HBEGF mRNA were observed as early as 15 min after transfer to $37^{\circ} \mathrm{C}$ (data not shown), with marked induction by $1 \mathrm{~h}$ (Fig. 2 $A)$. In contrast to HB-EGF and AR, induction of VPF and K6 transcripts was evident only after a further delay of at least $3 \mathrm{~h}$ (Figs. 1 and $2 A$ ). TGF- $\alpha$ was only minimally induced after prolonged periods of organ culture (Fig. 1), and EGF transcripts were undetectable at all time intervals tested (data not shown).

Effects of EGFR blockade on gene expression in human skin organ culture. Addition of PD153035 at the onset of organ culture inhibited the induction of AR, HB-EGF, VPF, and K6 after as little as $1 \mathrm{~h}$ (Fig. $2 \mathrm{~A}$ ). The inhibitory effects measured $24 \mathrm{~h}$ after treatment were strongly dose-dependent (Fig. $2 \mathrm{~B}$ ). The anti-EGFR mAb $225 \mathrm{IgG}$ also markedly and signifi- 

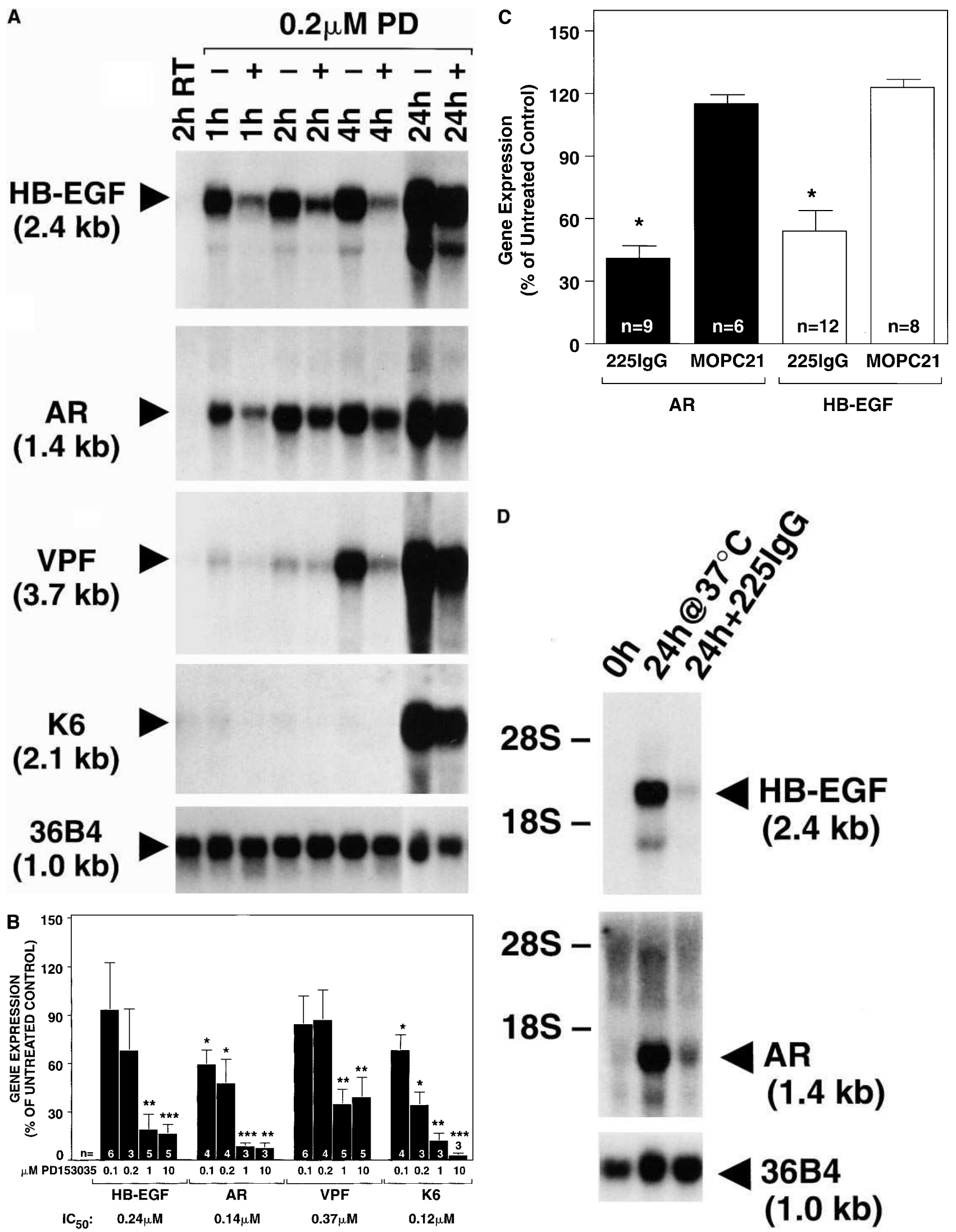

Figure 2. EGFR inhibitors block induction of HB-EGF, AR, VPF, and K6 gene expression in organ culture. (A) RNAs extracted from organ cultures treated with a single dose of $200 \mathrm{nM}$ PD153035 are compared to vehicle controls after 1,2, 4, and $24 \mathrm{~h}$ of treatment. The results of one of three experiments are shown, all of which yielded very similar results. $(B)$ Normalized hybridization signals obtained after $24 \mathrm{~h}$ of exposure to a single dose of PD153035 at the indicated concentration are expressed as a percentage of those obtained in DMSO vehicle controls. Values represent mean \pm SEM. Asterisks denote significant changes relative to the untreated controls $(* P<0.05, * * P<0.01, * * * P<0.001)$. (C) Normalized hybridization signals obtained $24 \mathrm{~h}$ after a single dose of $80 \mu \mathrm{g} / \mathrm{ml} 225 \mathrm{IgG}$ or MOPC21 are expressed as a percentage of the responses obtained for no treatment controls. Error bars indicate mean \pm SEM. The results of a representative experiment are shown in $D . P<0.001$ vs. untreated. 
A

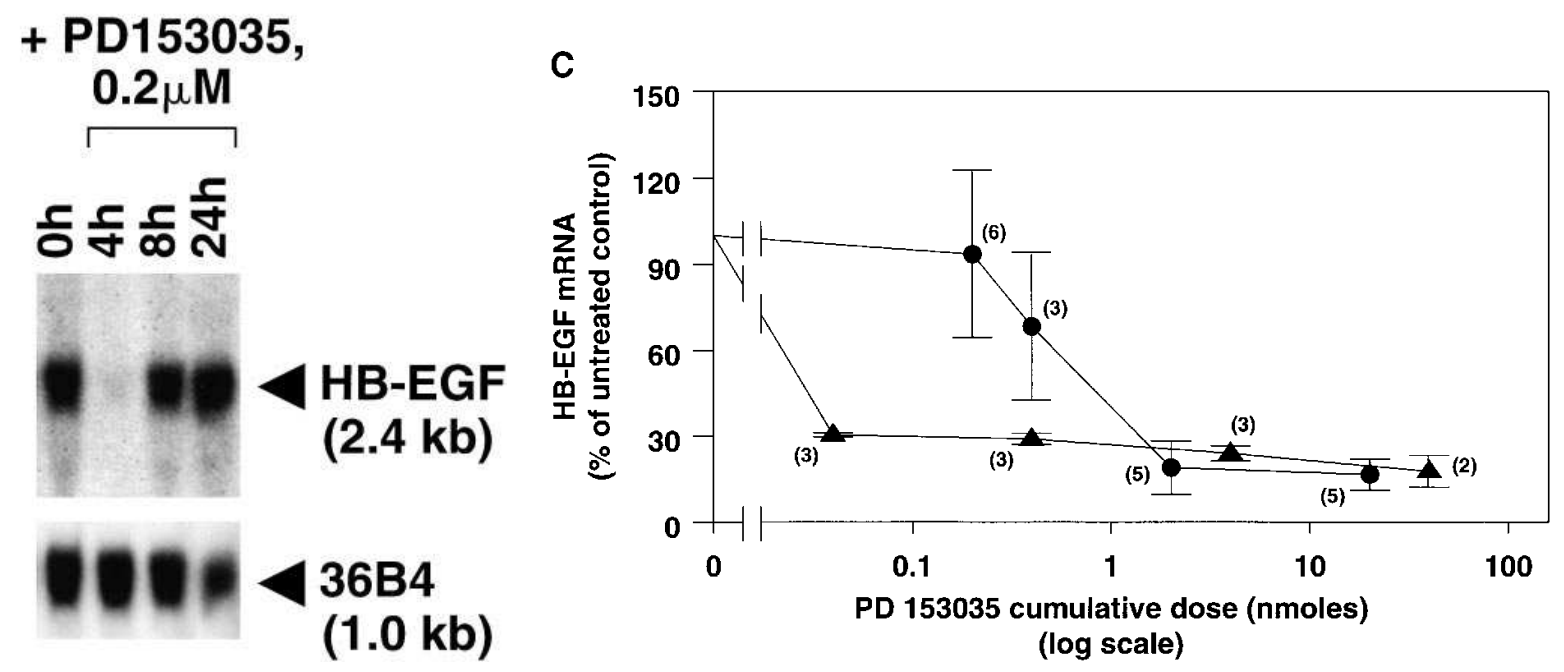

B

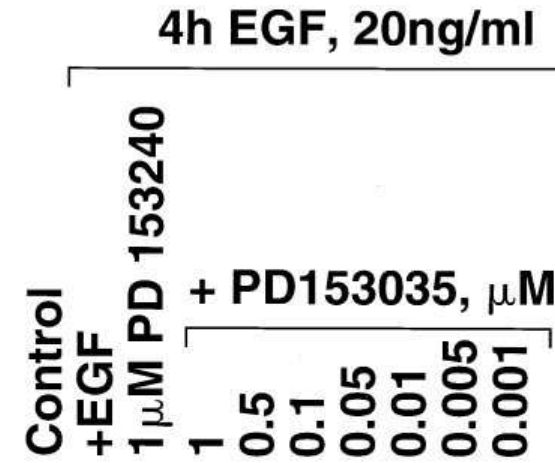

Dx @ Oh
harvest $24 h$

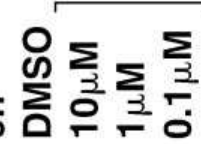

HB-EGF

(2.4 kb)
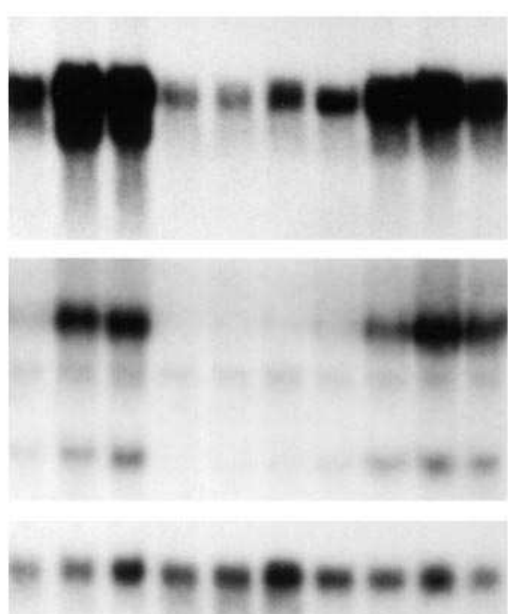

VPF

(3.7 kb)

36B4

(1.0 kb)

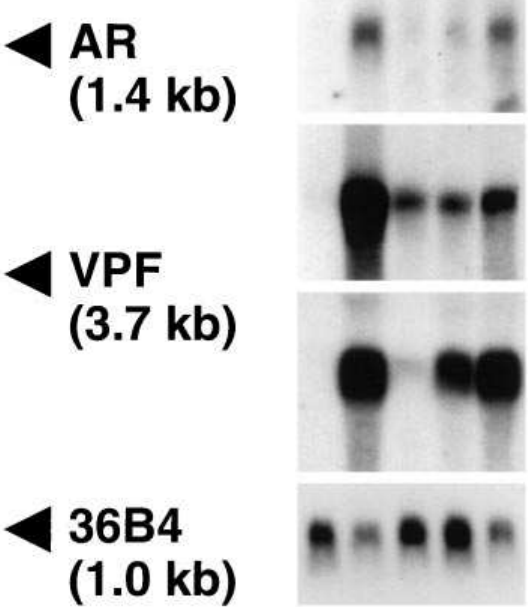

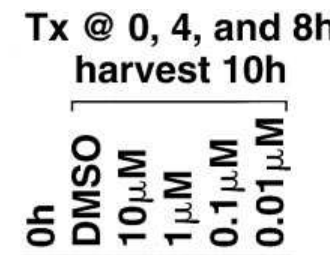

HB-EGF

(2.4 kb)

AR

(1.4 kb)

VPF

(3.7 kb)

K6

(2.1 kb)

(1.0 kb)

Figure 3. PD153035 loses potency with time in culture. (A) Time course of PD153035 inhibition of gene expression in RWG-KC. Postconfluent cultures were maintained as described in Methods, then treated with $200 \mathrm{nM}$ PD153035 for 4, 8, or $24 \mathrm{~h}$. (B) Inhibitory dose response of PD153035 against ligand-induced AR, HB-EGF, and VPF gene expression in MCDB-KC. Growth factor deprivation and EGF treatment were carried out as described in Methods. One hour before EGF treatment, the indicated concentrations of PD153035 or its biological inactive congener PD153240 were added. ( $C$ and $D$ ) PD153035 loses potency with time in organ culture. $(C)$ Quantitation of HB-EGF mRNA levels. Inhibi- 


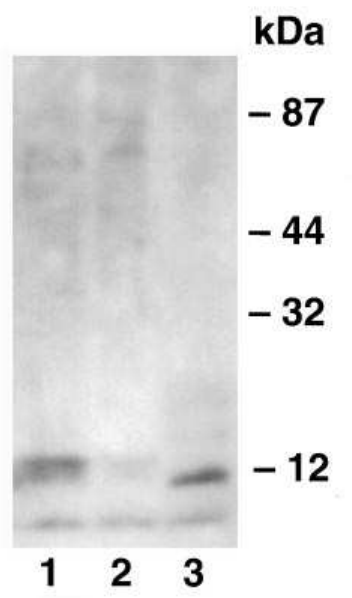

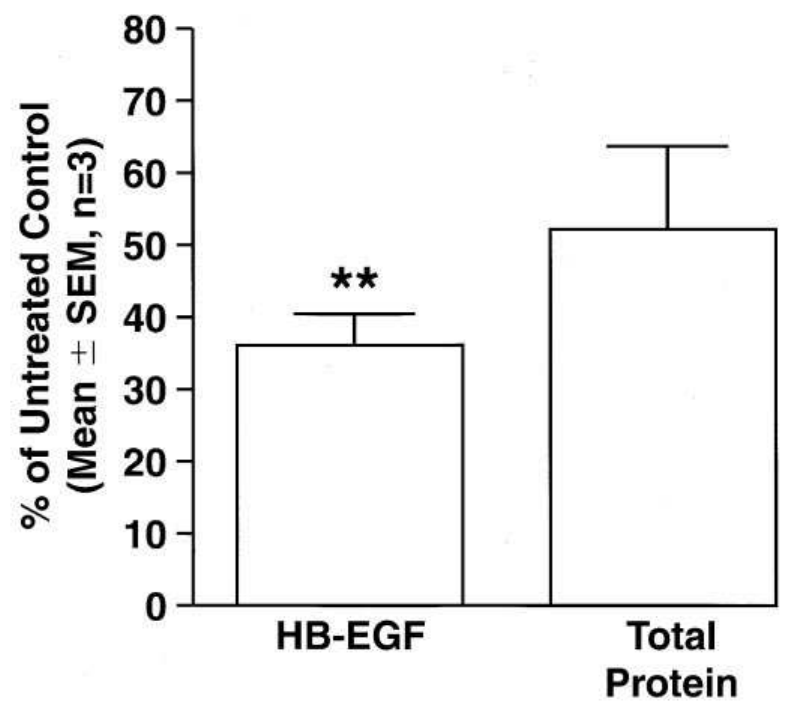

Figure 4. PD153035 reduces HB-EGF immunoreactive protein in organ culture. Keratome biopsies $\left(15 \mathrm{~cm}^{2}\right)$ were treated with $300 \mathrm{nM}$ PD153035 or DMSO control, and heparin-binding proteins were concentrated from conditioned medium by heparin-Sepharose chromatography as described in Methods. $(A)$ Western blot. Lane 1, no treatment control. Lane 2, PD153035-treated. Lane 3, recombinant human HB-EGF (500 pg). (B) Quantitations of total protein and immunoreactive HB-EGF obtained from $15 \mathrm{~cm}^{2}$ of keratome biopsy tissue. Error bars indicate mean \pm SEM $(n=3)$. **Indicates $P=0.005$ vs. DMSO control, by paired $t$ test. cantly inhibited the induction AR and HB-EGF transcripts, whereas the isotype control mAb MOPC21 had no effect (Fig. 2 C). Neither PD153035 nor 225 IgG had any effect on cell viability at concentrations up to $10 \mu \mathrm{M}$, as assessed by uptake of calcein-AM, a fluorogenic substrate that is cleaved to form a fluorescent, membrane-impermeant product only by living cells (43) (data not shown).

Potency of PD153035 as a function of incubation time. Substantial constitutive expression of HB-EGF mRNA was observed in postconfluent cultures of RWG-KC, and expression was strongly reduced $4 \mathrm{~h}$ after a single dose of PD153035. Near-complete loss of inhibitory activity, however, was observed after $8 \mathrm{~h}$ of treatment, and all inhibition was lost by $24 \mathrm{~h}$ (Fig. 3 A). When assayed after $4 \mathrm{~h}$, PD153035 inhibited the induction of HB-EGF in MCDB-KC by $50 \%$ between 10 and 50 $\mathrm{nM}$, in excellent agreement with the $\mathrm{IC}_{50}$ for inhibition of EGFR tyrosine kinase activity in A431 cells (32). Taken together, these results suggested that PD153035 undergoes a loss of potency with time in keratinocytes. We wondered whether this phenomenon might be responsible for the relatively low potency of this compound observed in organ culture $\left(\mathrm{IC}_{50}=\right.$ 120-370 nM; see Fig. 2 B). To address this question, keratomes were incubated for with various concentrations of PD153035 for $2 \mathrm{~h}$, whereupon the inhibitor was re-added at the same concentration. After an additional $2 \mathrm{~h}$ of incubation, the organ cultures were assayed for HB-EGF mRNA expression. Consistent with the cultured keratinocyte results, the dose response curve obtained under these conditions was shifted to the left by more than an order of magnitude relative to the 24-h treatment response (Fig. 3 C). A similar potency shift was observed for all four transcripts (HB-EGF, AR, VPF, and K6) when PD153035 was replenished every $4 \mathrm{~h}$ and the organ cultures were harvested at $10 \mathrm{~h}$ to allow sufficient time for induction of VPF and K6 transcripts to occur (Fig. $3 D$ ).

Production of $H B-E G F$ and total protein by organ cultures is inhibited by PD153035. As shown in Fig. 4, $A$ and $B$, two bands of $\sim 14 \mathrm{kD}$ could be detected in conditioned medium made briefly hypertonic at the end of a 3-d organ culture period (to enhance elution of tissue-bound proteins). When assessed on the basis of equivalent keratome surface areas, PD153035 significantly inhibited HB-EGF release by $64 \%$ (Fig. 4, $A$ and $B$ ). Interestingly, PD153035 also caused a 48\% reduction in the total amount of protein released into the organ culture medium; however, this effect was not statistically significant (Fig. $4 \mathrm{~B}$ ).

Epidermal outgrowth from human skin explant cultures. To explore further the functional consequences of EGFR inactivation in organ culture, we adapted a porcine skin epidermal outgrowth assay (30) to human skin, and measured epidermal outgrowth in the presence or absence of PD153035. Multiple outgrowths of keratinocytes could be seen extending away from the biopsy as early as $1 \mathrm{~d}$ after initiation of the explant cultures (data not shown), and were well-established by day 3 (Fig. 5 A). PD153035 treatment led to a pronounced

Figure 3 legend (Continued)

tion of HB-EGF gene expression is expressed as \% of untreated controls, mean \pm SEM. (O). Cultures were harvested 24 h after a single dose of the inhibitor. (A) Inhibitor was added at 0 and $2 \mathrm{~h}$, and cultures were harvested at $4 \mathrm{~h}$. To facilitate comparison of the two experiments, the data are shown as a function of total inhibitor dose per culture rather than concentration. ID I0 $_{\text {values: }}(\mathbf{\Delta}), 30 \mathrm{pmol} / \mathrm{culture} ;(\boldsymbol{O}), 790 \mathrm{pmol} / \mathrm{culture}$. $\mathrm{IC}_{50}$ values (determined by dividing the total dose by the culture volume): $(\boldsymbol{\Delta}), 30 \mathrm{pmol}$ cumulative dose $/ 3 \mathrm{ml} \mathrm{medium}=10 \mathrm{nM} ;(\boldsymbol{O}), 790 \mathrm{pmol} / 3$ $\mathrm{ml}$ medium $=263 \mathrm{nM}$. (D) Comparison of HB-EGF, AR, VPF, and K6 responses after $10 \mathrm{~h}$ vs. $24 \mathrm{~h}$ of organ culture. Organ cultures were maintained in the presence of the indicated concentrations of PD153035 for $24 \mathrm{~h}$ before harvest (left). Organ cultures were harvested after $10 \mathrm{~h}$. Amounts of PD153035 sufficient to generate the indicated concentrations were added to the cultures at 0,4 , and $8 \mathrm{~h}$ (right). Thus, by the end of $8 \mathrm{~h}$, the total concentrations were 3 times the amount shown. 

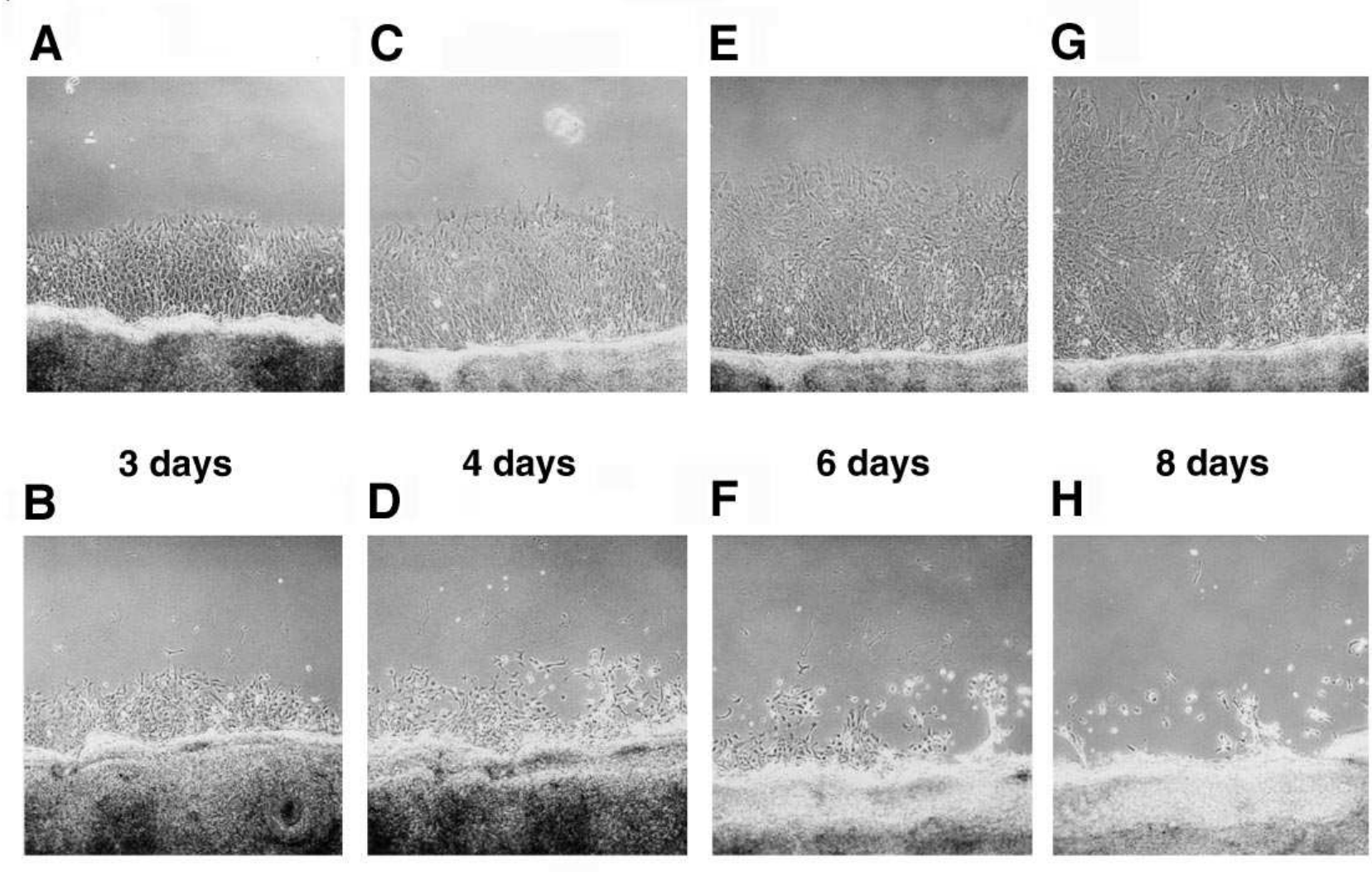

\section{PD 153035, 0.3 $\mu \mathrm{M}$}

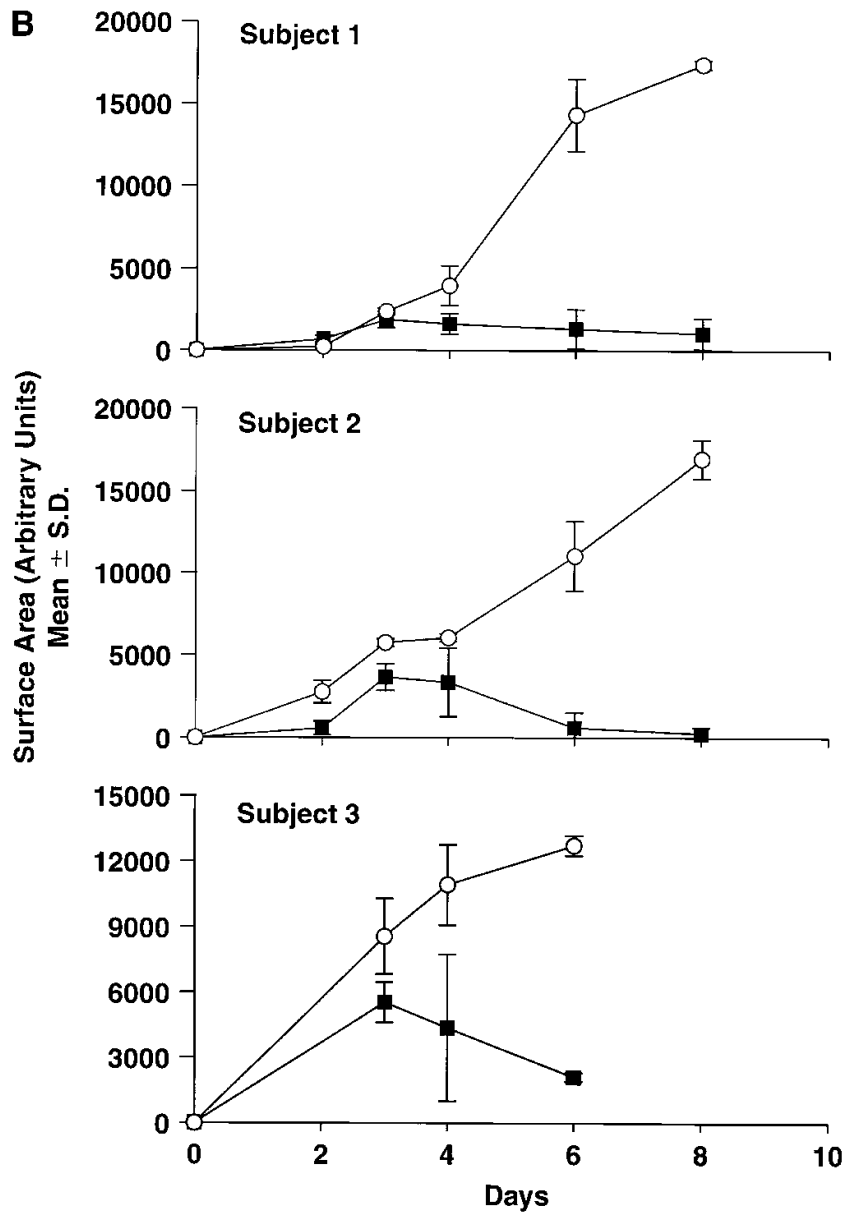

Figure 5. Epidermal outgrowth from human skin explant cultures. $(A)$ Photomicrographs from a representative experiment. Explant cultures were maintained for the indicated number of days in $300 \mathrm{nM}$ PD153035 or DMSO control as described in Methods. $A, C, E$, and $G$, DMSO controls; $B, D, F$, and $H$, PD153035-treated. Magnification, $\times 100$. $(B)$ Quantitation of outgrowth area. Average outgrowth area was determined as described in Methods. Each panel represents the results obtained for a single individual. (ם), PD153035-treated, $(O)$, DMSO controls. Error bars represent standard deviation of multiple (2-6) outgrowths from the same tissue fragment. Significance values determined for differences in average outgrowth area were as follows: day $2, P=0.63, n=2$; day $3, P=0.13, n=3$; day $4, P=0.10, n=3$; day $6, P=0.005, n=3$; day $8, P=0.006, n=2$. 


\section{6-day Normal Wounds}

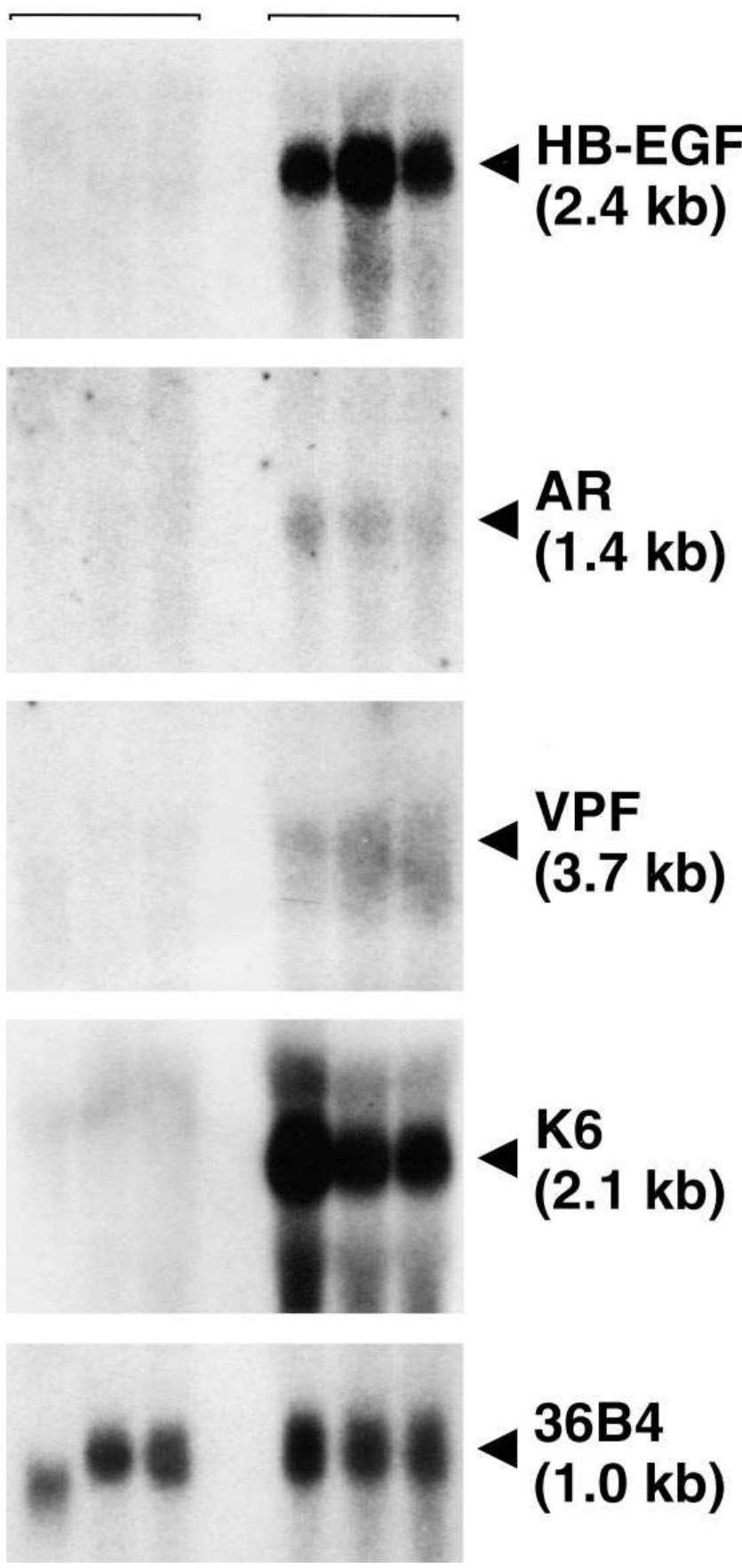

Figure 6. Expression of EGF-like growth factor, VPF, and K6 mRNAs in normal and wounded skin. Total RNA was isolated from skin samples of three different individuals before and six days after split thickness grafting, blotted to nylon membrane, and sequentially rehybridized against HB-EGF, AR, VPF, K6, and 36B4 cDNA probes.

reduction in outgrowth area, with marked differences in outgrowth size and morphology becoming evident by day 6 . Consistent with the onset of EGF-dependent keratinocyte proliferation in the porcine system (30), keratinocytes from untreated cultures began to increase rapidly in number beginning on day 4. In contrast, further outgrowth from samples incubated with PD153035 was completely inhibited, and preexisting outgrowths regressed, resulting in rounded cells apparently unable to establish cell-cell contacts. These differences were evident by day 4 , and became even more pronounced over prolonged incubation times (Fig. $5 A$ ). No significant differences in outgrowth area were detectable until day 6 (Fig. $5 B$ ), probably due to limited sample size.

Expression of EGF-like growth factors VPF and K6 in healing skin wounds. As shown in Fig. 6, AR, HB-EGF, VPF, and K6 transcripts were undetectable or expressed at very low levels in normal skin. In contrast, marked increases in HB-EGF and K6 mRNAs were seen in healing skin wounds harvested $6 \mathrm{~d}$ after injury (e.g., removal of split thickness skin grafts). VPF and AR transcript levels were also elevated, albeit not to the extent manifested by HB-EGF and K6.

\section{Discussion}

Signal transduction through the EGFR clearly has profound effects on keratinocyte proliferation and differentiation in vitro, and several lines of evidence point to the importance of this pathway during wound healing in vivo. The available data, however, have been insufficient to determine whether EGFR activation is necessary for cutaneous wound healing. To address this question, we have taken advantage of short-term organ and explant cultures of adult human skin. These experimental systems have emerged as powerful models for the study of wound healing $(30,44-46)$, as they permit the use of pharmacologic inhibitors that could be deleterious in vivo. Moreover, as opposed to cell culture studies, organ cultures constitute a fully differentiated tissue that retains dermal-epidermal interactions, and is subjected to trauma very similar to a normal cutaneous wound. Known wound healing-related events that have been observed in organ culture include increased collagenolytic (47) and plasminogen activator activity (48), enhanced keratinocyte migration (49), and induction of proteoglycans such as tenascin (50). More recently, epidermal outgrowth from porcine (30) and human (46) skin explants have been shown to be responsive to exogenous EGF. To our knowledge however, no previous studies have explored the effects of EGFR blockade on these responses.

To address this question, we treated human skin organ cultures with PD153035 (Fig. 2, $A$ and $B$ ) or the mAb $225 \mathrm{IgG}$ (Fig. $2 C$ ). PD153035 is a highly specific inhibitor of EGFR tyrosine kinase activity (32), and $225 \mathrm{IgG}$ competes for ligand binding and inhibits ligand-induced activation of the EGFR tyrosine kinase (33). Near-complete blockade of the pleiotropic organ culture response was observed after $24 \mathrm{~h}$ of PD153035 treatment, whereas the blockade produced by $225 \mathrm{IgG}$ was highly significant, but less complete. This difference may be explained by incomplete access of the IgG molecule to EGFR within the tissue fragments. The blockade of VPF by PD153035 was incomplete even at the highest doses tested, suggesting that additional signal transduction pathways may also be involved in its induction. Previous studies have shown that keratinocyte VPF expression can be induced by multiple cytokines and growth factors, including keratinocyte growth factor and TNF- $\alpha$ (51). Although we found no evidence for induction of these cytokine mRNAs in organ culture (data not shown), it is possible that increased amounts of these proteins could be se- 
creted and/or proteolytically cleaved during organ culture. Alternatively, it is also possible that local hypoxia could account for the EGFR-independent component (51).

Several lines of evidence indicate that the effects of PD153035 and $225 \mathrm{IgG}$ were not due to the induction of nonspecific cytotoxicity. First, the inactive congener PD153240 had no effect on the response of keratinocytes to EGF (Fig. 3 $B$ ), nor on the pleiotropic organ culture response (data not shown). Second, the $\mathrm{IC}_{50}$ values for inhibition of HB-EGF mRNA by PD153035 observed after $4 \mathrm{~h}(10 \mathrm{nM}$ in organ culture, Fig. $3 C, 10-50 \mathrm{nM}$ in keratinocyte culture, Fig. $3 B$ ) are similar to the published $\mathrm{IC}_{50}$ values for inhibition of EGFR tyrosine phosphorylation in intact A431 epidermoid carcinoma cells (15 nM) (32). Third, PD153035 markedly inhibited ligand-driven HB-EGF expression, whether keratinocytes were grown under conditions favoring differentiation (52) (Fig. $3 A$ ) or proliferation (53) (Fig. $3 B$ ). No evidence for cytotoxicity was observed in either culture system, as evidenced by trypan blue exclusion (data not shown). Fourth, neither PD153035 nor $225 \mathrm{IgG}$ had any effect on keratinocyte viability in organ cultures, as judged by calcein-AM uptake (data not shown). Fifth, we have previously demonstrated that RNA remains intact during organ culture, but is rapidly hydrolyzed when the tissue is rendered nonviable by freeze/thaw treatment (29). We observed no RNA degradation in response to PD153035 or $225 \mathrm{IgG}$ treatment, as evidenced by the comparable intactness of RNAs from treated and control cultures (Figs. 2 and 3; ethidium bromide staining patterns not shown). Finally, keratinocyte outgrowth was unaffected by the continuous presence of PD153035 for at least $3 \mathrm{~d}$ (Fig. 5). Taken together, these results indicate that neither the process of shortterm organ culture nor inhibition of EGFR tyrosine kinase activity exerts a significant effect on cell viability. We did, however, observe an apparent reduction in inhibitory potency for PD153035 over time in both keratinocyte and organ culture (Fig. 3). The observed loss in potency is unlikely to be due to cytotoxicity, as no cytotoxicity was observed. Moreover, this result cannot be explained readily by compensatory activation of other signal transduction pathways in organ culture, as the same effect was observed in cultured keratinocytes (Fig. $3 A$ ). Further analysis of the subcellular distribution and metabolic fate of PD153035 in keratinocytes and skin organ culture may provide insight into this phenomenon.

Consistent with the autocrine EGFR activation hypothesis, EGFR blockade by PD153035 reduced the release of HB-EGF into the medium by over $60 \%$. It is not surprising that EGFR blockade also reduced release of total protein, as EGF has long been known to have a general effect on protein synthesis (54). The presence of processed 14-kD HB-EGF in organ culture-conditioned medium is in agreement with previous studies demonstrating processed HB-EGF in porcine wound fluid as early as $24 \mathrm{~h}$ after injury (55). While this time course coincides with the appearance of mononuclear cells in the wound site (55), very few macrophages are present in normal skin (56). Thus, our observations strongly suggest that keratinocytes express and process HB-EGF before the appearance of mononuclear cells, a conclusion supported by immunostaining methods (57).

We investigated the biological consequences of inhibition of the EGFR signal using an epidermal outgrowth assay originally developed for porcine skin (30). In the porcine system, TGF- $\beta$-dependent epithelial cell migration occurs without proliferation until day 3 of culture. Marked proliferation ensues on day 4, as assessed by BrdU incorporation (30). Our studies demonstrate that EGFR blockade completely abolishes the proliferative phase of epidermal outgrowth, whereas it has little or no detectable effect on the earlier migration phase. Our results suggest that EGFR activation is necessary for keratinocyte proliferation during the early phases of cutaneous wound repair. The availability of EGFR knockout mice and pharmacologic quantities of highly specific EGFR inhibitors should make it possible to extend these observations to the in vivo environment.

Binding to proteoglycans is thought to be an important mechanism of growth factor regulation during wound healing $(58,59)$. An interesting observation in both organ culture and in healing wounds is that injury appears to induce selectively the expression of EGF-like growth factors that bind heparin; e.g., HB-EGF and AR vs. TGF- $\alpha$ and EGF. Tenascin is a large sulfated proteoglycan whose presence in the underlying dermis is closely associated with epidermal proliferation in wound healing and development as well as psoriasis $(50,60)$. We suggest that that interactions between EGF-like growth factors and sulfated proteoglycans such as tenascin may be important in dictating patterns of reepithelialization during wound healing.

Taken together, these studies demonstrate that EGFR activation is necessary not only for amplification of the wound healing signal, but also for its transmission to critical downstream effector mechanisms, including alterations in keratinocyte proliferation and cytoskeletal architecture as well as capillary permeability and angiogenesis. They also underscore the value of skin organ culture as an experimental system for the study of early wound healing events. Future studies will exploit this system to identify the initial signal(s) for EGFR ligand expression, define the molecular links between EGFR activation and TGF- $\beta$ signaling, and elucidate the mechanism of growth arrest associated with EGFR inactivation.

\section{Acknowledgments}

We thank Drs. David Fry and W.R. Leopold (Parke-Davis Pharmaceutical Research, Ann Arbor, MI) for their generous provision of PD153035 and PD153240, and Dr. John Mendelsohn of the Memorial Sloan-Kettering Cancer Center for his generous gift of mAb $225 \mathrm{IgG}$. The invaluable assistance of Laura VanGoor, Carolyn Petersen, Robin Gardner, and Ted Hamilton is gratefully acknowledged.

Portions of this work were supported by the National Institutes for Arthritis, Musculoskeletal and Skin Diseases, National Institutes of Health (R29 AR40016 and R01 AR42248), the Dermatology Foundation, and the Babcock Memorial Trust. Dr. Elder is supported by the Ann Arbor Veterans Administration Hospital.

\section{References}

1. Clark, R.A.F. 1996. The Molecular and Cellular Biology of Wound Repair. Plenum Publishing Corporation, New York. 611 pgs.

2. Mansbridge, J.N., and A.M. Knapp. 1987. Changes in keratinocyte maturation during wound healing. J. Investig. Dermatol. 89 (3):253-263.

3. Werner, S., H. Smola, X. Liao, M.T. Longaker, T. Krieg, P.H. Hofschneider, and L.T. Williams. 1994. The function of KGF in morphogenesis of epithelium and reepithelialization of wounds. Science (Wash. DC). 266 (5186): 819-822.

4. Elder, J. 1994. Transforming growth factor-alpha and related growth factors. In Epidermal Growth Factors and Cytokines. T. Luger and T. Schwarz, editors. Marcel Dekker, Inc., New York. 205-240.

5. Nanney, L.B., and L.E. King. 1996. Epidermal growth factor and trans- 
forming growth factor-alpha. In The Molecular and Cellular Biology of Wound Repair. R.A.F. Clark, editor. Plenum Publishing Corporation, New York.

6. Barnard, J.A., R. Graves Deal, M.R. Pittelkow, R. DuBois, P. Cook, G.W. Ramsey, P.R. Bishop, L. Damstrup, and R.J. Coffey. 1994. Auto- and cross-induction within the mammalian epidermal growth factor-related peptide family. J. Biol. Chem. 269 (36):22817-22822.

7. Coffey, R.J., Jr., R. Derynck, J.N. Wilcox, T.S. Bringman, A.S. Goustin, H.L. Moses, and M.R. Pittelkow. 1987. Production and auto-induction of transforming growth factor-alpha in human keratinocytes. Nature (Lond.). 328 (6133):817-820.

8. Cook, P.W., P.A. Mattox, W.W. Keeble, M.R. Pittelkow, G.D. Plowman, M. Shoyab, J.P. Adelman, and G.D. Shipley. 1991. A heparin sulfate-regulated human keratinocyte autocrine factor is similar or identical to amphiregulin. Mol. Cell Biol. 11 (5):2547-2557.

9. Hashimoto, K., S. Higashiyama, H. Asada, E. Hashimura, T. Kobayashi, K. Sudo, T. Nakagawa, D. Damm, K. Yoshikawa, and N. Taniguchi. 1994. Heparin-binding epidermal growth factor-like growth factor is an autocrine growth factor for human keratinocytes. J. Biol. Chem. 269 (31):20060-20066.

10. Coffey, R., Jr., R. Graves-Deal, P.J. Dempsey, R.H. Whitehead, and M.R. Pittelkow. 1992. Differential regulation of transforming growth factor alpha autoinduction in nontransformed and transformed epithelial cell. Cell Growth Differ. 3 (6):347-354.

11. Stoll, S.W., and J.T. Elder. 1995. EGF receptor activation regulates expression of multiple keratinocyte-derived growth factor rnRNAs by increasing transcript stability. J. Investig. Dermatol. 104 (4):675a (Abstr.).

12. Beerli, R.R., D. Graus Porta, K. Woods Cook, X. Chen, Y. Yarden, and N.E. Hynes. 1995. Neu differentiation factor activation of ErbB-3 and ErbB-4 is cell-specific and displays a differential requirement for ErbB-2. Mol. Cell Biol. 15 (12):6496-6505.

13. Poumay, Y., and M.R. Pittelkow. 1995. NDF/heregulins are expressed by proliferating cultured keratinocytes, but activate HER2 only in growtharrested cultures and suppress expression of differentiation markers. J. Investig. Dermatol. 104:574a (Abstr.).

14. Danilenko, D.M., B.D. Ring, J.Z. Lu, J.E. Tarpley, D. Chang, N. Liu, D. Wen, and G.F. Pierce. 1995. Neu differentiation factor upregulates epidermal migration and integrin expression in excisional wounds. J. Clin. Invest. 95 (2): $842-851$

15. Klein, S.B., G.J. Fisher, T.C. Jensen, J. Mendelsohn, J.J. Voorhees, and J.T. Elder. 1992. Regulation of TGF-alpha expression in human keratinocytes: PKCdependent and independent pathways. J. Cell Physiol. 151 (2):326-336.

16. Elder, J.T., C.I. Sartor, D.K. Boman, S. Benrazavi, G.J. Fisher, and M.R. Pittelkow. 1992. Interleukin-6 in psoriasis: expression and mitogenicity studies. Arch. Dermatol. Res. 284 (6):324-332.

17. Carpenter, G., and S. Cohen. 1990. Epidermal growth factor. J. Biol. Chem. 265 (14):7709-7712.

18. Stoscheck, C.M., L.B. Nanney, and L.E. King, Jr. 1992. Quantitative determination of EGF-R during epidermal wound healing. J. Investig. Dermatol. 99 (5):645-649.

19. Detmar, M., K.-T. Yeo, J. Nagy, L. Van De Water, L. Brown, B.R. Berse, S. Ledbetter, and H. Dvorak. 1995. Keratinocyte-derived vascular permeability factor (vascular endothelial growth factor) is a potent mitogen for dermal microvascular endothelial cells. J. Investig. Dermatol. 105:44-50.

20. Paladini, R.D., K. Takahashi, N.S. Bravo, and P.A. Coulombe. 1996. Onset of re-epithelialization after skin injury correlates with a reorganization of keratin filaments in wound edge keratinocytes: defining a potential role for keratin 16. J. Cell Biol. 132 (3):381-397.

21. Jiang, C.K., T. Magnaldo, M. Ohtsuki, I.M. Freedberg, F. Bernerd, and M. Blumenberg. 1993. Epidermal growth factor and transforming growth factor alpha specifically induce the activation- and hyperproliferation-associated keratins 6 and 16. Proc. Natl. Acad. Sci. USA. 90 (14):6786-6790.

22. Taipale, J., K. Koli, and J. Keski-Oja. 1992. Release of transforming growth factor-beta 1 from the pericellular matrix of cultured fibroblasts and fibrosarcoma cells by plasmin and thrombin. J. Biol. Chem. 267 (35):2537825384.

23. Grant, G.A., G.I. Goldberg, S.M. Wilhelm, C. He, and A.Z. Eisen. 1992. Activation of extracellular matrix metalloproteases by proteases and organomercurials. Matrix Suppl. 1:217-223.

24. Bugge, T.H., K.W. Kombrinck, M.J. Flick, C.C. Daugherty, M.J. Danton, and J.L. Degen. 1996. Loss of fibrinogen rescues mice from the pleiotropic effects of plasminogen deficiency. Cell. 87 (4):709-719.

25. Jensen, P.J., and U. Rodeck. 1993. Autocrine/paracrine regulation of keratinocyte urokinase plasminogen activator through the TGF-alpha/EGF receptor. J. Cell. Physiol. 155 (2):333-339.

26. Brown, G.L., L.B. Nanney, J. Griffen, A.B. Cramer, J.M. Yancey, L.D. Curtsinger, L. Holtzin, G.S. Schultz, M.J. Jurkiewicz, and J.B. Lynch. 1989. Enhancement of wound healing by topical treatment with epidermal growth factor [see comments]. N. Engl. J. Med. 321(2):76-79.

27. Nanney, L.B. 1990. Epidermal and dermal effects of epidermal growth factor during wound repair. J. Investig. Dermatol. 94 (5):624-629.

28. Rheinwald, J., and H. Green. 1977. Epidermal growth factor and the multiplication of cultured human epidermal keratinocytes. Nature (Lond.). 265 (5593):421-424.
29. Elder, J.T., A. Tavakkol, S.B. Klein, M.E. Zeigler, M. Wicha, and J.J. Voorhees. 1990. Protooncogene expression in normal and psoriatic skin. J. Investig. Dermatol. 94 (1):19-25.

30. Hebda, P.A. 1988. Stimulatory effects of transforming growth factorbeta and epidermal growth factor on epidermal cell outgrowth from porcine skin explant cultures. J. Investig. Dermatol. 91 (5):440-445.

31. Garner, W.L., J.L. Rodriguez, C.G. Miller, G.O. Till, R.S. Rees, D.J. Smith and D.G. Remick. 1994. Acute skin injury releases neutrophil chemoattractants. Surgery (St. Louis). 116 (1):42-48.

32. Fry, D.W., A.J. Kraker, A. McMichael, L.A. Ambroso, J.M. Nelson, W.R. Leopold, R.W. Connors, and A.J. Bridges. 1994. A specific inhibitor of the epidermal growth factor receptor tyrosine kinase. Science (Wash. DC). 265: 1093-1095.

33. Sunada, H., B.E. Magun, J. Mendelsohn, and C.L. MacLeod. 1986. Monoclonal antibody against epidermal growth factor receptor is internalized without stimulating receptor phosphorylation. Proc. Natl. Acad. Sci. USA. 83 (11):3825-3829.

34. Voorhees, J.J., E.A. Duell, L.J. Bass, J.A. Powell, and E.R. Harrell 1972. Decreased cyclic AMP in the epidermis of lesions of psoriasis. Arch. Dermatol. 105 (5):695-701.

35. Elder, J.T., G.J. Fisher, Q.Y. Zhang, D. Eisen, A. Krust, P. Kastner, P. Chambon, and J.J. Voorhees. 1991. Retinoic acid receptor gene expression in human skin. J. Investig. Dermatol. 96 (4):425-433.

36. Pittelkow, M.R., J. Wille, Jr., and R.E. Scott. 1986. Two functionally distinct classes of growth arrest states in human prokeratinocytes that regulate clonogenic potential. J. Investig. Dermatol. 86 (4):410-417.

37. Elder, J.T., G.J. Fisher, P.B. Lindquist, G.L. Bennett, M.R. Pittelkow, R. Coffey, Jr., L. Ellingsworth, R. Derynck, and J.J. Voorhees. 1989. Overexpression of transforming growth factor alpha in psoriatic epidermis. Science (Wash. DC). 243 (4892):811-814.

38. Elder, J., A. Kaplan, M. Cromie, S. Kang, and J. Voorhees. 1996. Retinoid induction of CRABP II rnRNA in human fibroblasts: use as a retinoid bioassay. J. Investig. Dermatol. 106 (3):517-521.

39. Plowman, G.D., J.M. Green, V.L. McDonald, M.G. Neubauer, C.M Disteche, G.J. Todaro, and M. Shoyab. 1990. The amphiregulin gene encodes a novel epidermal growth factor-related protein with tumor-inhibitory activity. Mol. Cell Biol. 10 (5):1969-1981.

40. Leung, D.W., G. Cachianes, W.J. Kuang, D.V. Goeddel, and N. Ferrar. 1989. Vascular endothelial growth factor is a secreted angiogenic mitogen. Science (Wash. DC). 246 (4935):1306-1309.

41. Ausubel, F.M., R. Brent, R.E. Kingston, D.D. Moore, J.G. Seidman, J.A. Smith, K. Struhl, L.M. Albright, D.M. Coen, and A. Varki. 1988. Current protocols in molecular biology. Vol. 1. K. Janssen, editor. Wiley and Sons, New York

42. Laemmli, U.K. 1970. Cleavage of structural proteins during the assembly of the head of bacteriophage T4. Nature (Lond.). 227 (259):680-685.

43. Papadopoulos, N.G., G.V. Dedoussis, G. Spanakos, A.D. Gritzapis, C.N. Baxevanis, and M. Papamichail. 1994. An improved fluorescence assay for the determination of lymphocyte-mediated cytotoxicity using flow cytometry. $J$. Immunol. Methods. 177 (1-2):101-111.

44. Reaven, E.P., and A.J. Cox. 1968. Behavior of adult human skin in organ culture. II. Effects of cellophane tape stripping, temperature, oxygen tension, pH and serum. J. Investig. Dermatol. 50 (2):118-128.

45. Sarkany, I., K. Grice, and G.A. Caron. 1965. Organ culture of adult human skin. Br. J. Dermatol. 77:65-76.

46. Bhora, F.Y., B.J. Dunkin, S. Batzri, H.M. Aly, B.L. Bass, A.N. Sidawy, and J.W. Harmon. 1995. Effect of growth factors on cell proliferation and epithelialization in human skin. J. Surg. Res. 59 (2):236-244.

47. Eisen, A.Z. 1969. Human skin collagenase: localization and distribution in normal human skin. J. Investig. Dermatol. 52 (5):442-448.

48. Morioka, S., G.S. Lazarus, and P.J. Jensen. 1987. Involvement of urokinase-type plasminogen activator in acantholysis induced by pemphigus IgG. $J$. Investig. Dermatol. 89 (5):474-478.

49. Marks, R., B. Bhogal, and R.P. Dawber. 1972. The migratory property of epidermis in vitro. Arch. Dermatol. Forsch. 243 (3):209-220.

50. Mackie, E.J., W. Halfter, and D. Liverani. 1988. Induction of tenascin in healing wounds. J. Cell Biol. 107 (6 Pt 2):2757-2767.

51. Dvorak, H.F., L.F. Brown, M. Detmar, and A.M. Dvorak. 1995. Vascular permeability factor/vascular endothelial growth factor, microvascular permeability, and angiogenesis. Am. J. Pathol. 146 (5):1029-1039.

52. Rheinwald, J.G., and H. Green. 1975. Serial cultivation of strains of human epidermal keratinocytes: the formation of keratinizing colonies from single cells. Cell. 6 (3):331-343.

53. Wille, J., Jr., M.R. Pittelkow, G.D. Shipley, and R.E. Scott. 1984. Integrated control of growth and differentiation of normal human prokeratinocytes cultured in serum-free medium: clonal analyses, growth kinetics, and cell cycle studies. J. Cell. Physiol. 121 (1):31-44.

54. Thomas, G., J. Martin-Perez, M. Siegmann, and A.M. Otto. 1982. The effect of serum, EGF, PGF2 alpha and insulin on S6 phosphorylation and the initiation of protein and DNA synthesis. Cell. 30 (1):235-242.

55. Marikovsky, M., P. Vogt, E. Eriksson, J.S. Rubin, W.G. Taylor, J. Sasse, and M. Klagsbrun. 1996. Wound fluid-derived heparin-binding EGF-like 
growth factor (HB-EGF) is synergistic with insulin-like growth factor-I for Balb/MK keratinocyte proliferation. J. Investig. Dermatol. 106 (4):616-621.

56. Meunier, L., Z. Bata-Csorgo, and K.D. Cooper. 1995. In human dermis, ultraviolet radiation induces expansion of a CD36+CD11b + CD1 - macrophage subset by infiltration and proliferation; CD1+ Langerhans-like dendritic antigen-presenting cells are concomitantly depleted. J. Investig. Dermatol. 105 (6):782-788

57. McCarthy, D.W., M.T. Downing, D.R. Brigstock, M.H. Luquette, K.D. Brown, M.S. Abad, and G.E. Besner. 1996. Production of heparin-binding epidermal growth factor-like growth factor (HB-EGF) at sites of thermal injury in pediatric patients. J. Investig. Dermatol. 106 (1):49-56.

58. Flaumenhaft, R., and D.B. Rifkin. 1992. The extracellular regulation of growth factor action. Mol. Biol. Cell. 3 (10):1057-1065.

59. Cook, P.W., N.M. Ashton, C.E. Karkaria, D.C. Siess, and G.D. Shipley. 1995. Differential effects of a heparin antagonist (hexadimethrine) or chlorate on amphiregulin, basic fibroblast growth factor, and heparin-binding EGF-like growth factor activity. J. Cell. Physiol. 163 (2):418-429.

60. Schalkwijk, J., P.M. Steijlen, I.M. van Vlijmen-Willems, B. Oosterling, E.J. Mackie, and A.A. Verstraeten. 1991. Tenascin expression in human dermis is related to epidermal proliferation. Am. J. Pathol. 139 (5):1143-1150. 